\title{
IV. Toxikologie.
}

\section{Hagnesia in Verbindung mit Zucker bei Vergif- tungen.}

Carles hat versucht, die Wirksamkeit der Magnesia als Antidot der arsenigen Säure durch einen Zusatz von Zucker zu erhöhen, indem er glaubte, dass die Magnesia dadurch löslich werde; allein es fand sich, dass die arsenigsaure Magnesia in Zucker löslich sei und dass sonach der Zucker, statt vortheilhaft, nur schädlich wirke. Hingegen bei Blei-, Kupfer-, Quecksilber und Antimon-Salzen ist der Zuckerzusatz zur Magnesia entschieden vortheilhaft, indem er die Zersetzung derselben beschleunigt und erleichtert, ohne eine Verbindung damit einzugehen, und in einigen Fällen wirkt der Zucker an sich, indem er die Oxyde reducirt. Wo dieses stattfindet, würde Honig dem Zucker noch vorzuziehen sein. (Americ. Journ. of Pharm. Vol. XLII. Nr. VI. Third. Ser. Novbr. 1870. Vol. XVIII. Nr. VI. p.510. Aus Repertoire de Pharm. Août 1870.).

$W p$. 